\title{
BIBLIOTECA COMUNITÁRIA BRUNO FENZL: UM ESTUDO DE CASO DE SEU PAPEL EDUCATIVO NO CONTEXTO DA COMUNIDADE DE CARUARÁ, MARAHÚ E PARAISO NA ILHA DE MOSQUEIRO
}

\author{
TELMA SOCORRO SILVA SOBRINHO* \\ CLAUDIA SALDANHA COIMBRA*
}

\begin{abstract}
RESUMO
Apresenta estudo de caso realizado na Biblioteca Bruno Fenzl, uma das unidades do Instituto Ampliar - Organização não Governamental (ONG) - que visa desenvolver trabalhos de sensibilização ambiental nas praias de Caruará, Marahú e Paraiso na llha de Mosqueiro Belém-PA. Tem como objetivo analisar a forma como a Biblioteca Comunitária Bruno Fenzl contribui, dando apoio educacional e promovendo incentivo à leitura a estudantes pertencentes a comunidade onde está inserida. Adota uma abordagem qualitativa onde a coleta de dados se deu por meio de entrevistas individuais, seguindo um roteiro estruturado, utilizando-se da técnica metodológica de análise do desenho. Os resultados revelam que apesar de estarmos na era da internet, ainda assim, o livro impresso é um suporte bastante atrativo quando se trata de práticas de leitura.
\end{abstract}

PALAVRAS-CHAVE: Biblioteca comunitária. Função pedagógica da biblioteca comunitária. Leitura. Desenho infantil.

COMMUNITY LIBRARY BRUNO FENZL:

A CASE STUDY OF ITS EDUCATIONAL ROLE IN THE CONTEXT OF THE COMMUNITY OF CARUARÁ, MARAHÚ AND PARAISO IN MOSQUEIRO ISLAND

\begin{abstract}
It presents a case study of the Bruno Fenzl Library, which originates in the Ampliar Institute, a non-governmental organization (NGO), na environmental awareness project in the beaches of Caruará, Marahú and Paraíso on Mosqueiro Island, Belém-PA. It aims to analyze how the Bruno Fenzl Community Library contributes to providing educational support, as well as encouraging reading for students belonging to the community where it is inserted. It adopts a qualitative approach where data collection took place through individual
\end{abstract}

* Professora da Faculdade de Biblioteconomia da Universidade Federal do Pará, na área de Representação Temática da Informação, leitura e bibliotecas escolares.

** Bibliotecária e Pedagoga, atuando em Escola do Município de Belém-PA. 
interviews, following a structured script, using a methodological technique of drawing analysis. The results show that even though we are in the age of the internet, the subjects of the research have a printed book as a very attractive medium when it comes to reading practices.

KEYWORDS: Community library. The pedagogical role of the community library. Reading. Child's drawing.

\section{INTRODUÇÃO}

Sabe-se que apesar do grande fluxo de informações presentes na sociedade atual, muitas comunidades carecem de espaços onde possam ter contato com materiais ou serviços que supram suas necessidades informacionais. Dessa forma, as bibliotecas comunitárias podem cumprir este papel social ao fornecerem subsídios no âmbito educacional, cultural e de incentivo à leitura, atuando também como um espaço de ação pedagógica, haja vista que muitas bibliotecas escolares não possuem recursos ou uma infraestrutura adequada para atrair leitores e atender os anseios de seus usuários.

A pesquisa foi realizada para responder ao seguinte questionamento: De que maneira a Biblioteca Comunitária Bruno Fenzl se articula com a comunidade de Mosqueiro visando o incentivo à leitura e dando apoio didático pedagógico aos estudantes de seus arredores?

Para isso, será realizado um estudo de caso da Biblioteca Bruno Fenzl. Esta biblioteca pertence ao Instituto Ampliar, Organização não Governamental (ONG) derivada de um projeto de extensão do Centro de Filosofia e Ciências Humanas (CFCH), da Universidade Federal do Pará (UFPA), para desenvolver trabalhos de sensibilização ambiental nas praias de Caruará, Marahú e Paraíso, localizadas na llha de Mosqueiro. A ilha é um distrito do Município de Belém-PA. A ONG foi criada em 1998, e recentemente passou a agregar um outro projeto de extensão intitulado "Ações afirmativas em Bibliotecas de Escolas Públicas e Bibliotecas Comunitárias em Belém-PA", que pertence a Faculdade de Biblioteconomia do Instituto de Ciências Sociais Aplicadas - ICSA, também da UFPA.

Dessa forma, a pesquisa tem como objetivo analisar como a Biblioteca Comunitária Bruno Fenzl contribui para dar apoio educacional, bem como incentivo à leitura aos estudantes pertencentes a comunidade de Mosqueiro, distrito de Belém-PA. 
O estudo aplicado possui caráter descritivo onde a coleta de dados se deu por meio de entrevistas individuais, seguindo um roteiro estruturado, utilizando-se a técnica metodológica de análise do desenho como procedimento para obter as informações desejadas.

\section{BIBLIOTECA COMUNITÁRIA: UM CONCEITO EM CONSTRUÇÃO}

Atualmente ainda não há um conceito consistente acerca das bibliotecas comunitárias, uma vez que as considerações achadas divergem entre opiniões de diversos teóricos, sendo que grande parte da literatura científica sobre esse assunto ainda trata a biblioteca comunitária dentro da perspectiva de bibliotecas públicas. Bohm (2009) revela que mesmo após trinta anos da concepção do termo "biblioteca comunitária" na literatura brasileira, percebe-se que ainda há muitas controvérsias a respeito do seu conceito, sendo necessários mais estudos teóricos sobre essa temática.

Muitos autores classificavam as bibliotecas comunitárias como sendo biblioteca pública no sentido mantenedor, na verdade elas são públicas com relação ao seu acesso, mas geralmente são mantidas com os recursos da própria comunidade ou de colaboradores. Almeida Júnior (1997), por exemplo, acredita que pelo fato de as bibliotecas comunitárias atuarem junto a segmentos mais carentes em bairros periféricos, elas na verdade seriam uma extensão da biblioteca pública. Já Wessfll (2011) afirma que essa visão levou muitas pessoas a interpretarem essas bibliotecas como sendo o mesmo que bibliotecas públicas e bibliotecas populares. A comparação se dá pelo fato de as bibliotecas comunitárias serem criadas em locais onde o poder público não oferece este tipo de serviço.

As bibliotecas comunitárias surgem de uma necessidade local por um espaço onde seja possível buscar não só informação, mas também atividades artísticas e culturais que contribuam para a emancipação social e consequente melhoria da localidade ao seu redor. Diferente de Almeida Júnior (1997), Machado (2008, p. 61) revela que:

[...] a biblioteca comunitária, como se apresenta hoje na sociedade brasileira, pode ser considerada um outro tipo de biblioteca, pois vem sendo criada seguindo os princípios da autonomia, da flexibilidade e da articulação local, o que amplia as possibilidades de atuação e de inserção na sociedade. Outro fator que nos leva a considerá-la diferente é pela forma de atuação estar muito mais ligada à ação cultural do que aos serviços de organização e tratamento da informação. 
A biblioteca comunitária difere da biblioteca pública pelo fato dela surgir na comunidade como uma fonte alternativa para suprir as necessidades informacionais das pessoas que ali estão inseridas, por meio de arrecadação de materiais voltados à educação em todos os níveis.

Assim, as bibliotecas comunitárias podem ser consideradas um novo tipo de unidade de informação que pretende democratizar, ou seja, facilitar o acesso das comunidades carentes aos diversos tipos de materiais informacionais, partindo de uma iniciativa local, que mesmo na maioria das vezes, sem apoio governamental, se une para criar um espaço de emancipação intelectual, social, cultural que vise o exercício da cidadania.

\subsection{Função Educacional das Bibliotecas Comunitárias}

Como já foi dito, as bibliotecas comunitárias surgem a partir da iniciativa de um grupo de pessoas de uma determinada localidade, podendo ou não ter apoio governamental. Nessa premissa, seu objetivo é realizar a emancipação social e proporcionar um espaço educativo para atender usuários com diferentes anseios informacionais. De acordo com Castro, Oliveira e Alves (2014) a biblioteca comunitária precisa estar preparada para receber um público diversificado, e de gostos heterogêneos, visto que seu atendimento abrange desde crianças que procuram um livro mais ilustrativo até o aluno universitário que vai em busca de informações para complementar sua pesquisa científica.

Entende-se que as bibliotecas comunitárias assim como as bibliotecas públicas, acabam assumindo para si uma função educativa, visto que na realidade brasileira as escolas ainda não dispõem em sua totalidade deste equipamento educativo. Porém, para além de muitas das vezes substituir as bibliotecas escolares, as bibliotecas comunitárias agregam atividades sociais que visam potencializar talentos, por meio de projetos artísticos, culturais e outras ações que procuram fazer com que as crianças e jovens tenham uma ocupação, e assim a oportunidade de não se voltar para a marginalidade.

Assim, as bibliotecas comunitárias vêm justamente disponibilizar e ampliar o acesso à informação, sobretudo em localidades que carecem de mais auxílio das instituições governamentais. Nesse contexto, as bibliotecas comunitárias se constituem como uma ação afirmativa que pode assumir o papel pedagógico focado no combate à baixa escolaridade e desempenho 
escolar de estudantes de comunidades carentes. Para isso, atividades artísticas, culturais e de incentivo à leitura são fundamentais para que crianças e jovens se sintam mais motivados a frequentar esse ambiente e com isso adquirir mais conhecimentos que os incentivem ao exercício da cidadania.

\section{O DESENHO COMO FORMA DE REPRESENTAÇÃO}

O desenho é uma das formas de comunicação não verbal mais antiga de nossa civilização. Nos diversos campos da ciência é bastante utilizado na avaliação do desenvolvimento infantil, a fim de se obter maior entendimento das fases de vida das crianças, que por sua vez, são muito importantes para intervenções psicológicas, haja vista que os desenhos podem revelar sentimentos, pensamentos, traumas e desejos. Dessa forma, o desenho vem se destacando cada vez mais como um instrumento metodológico de pesquisa não só com crianças, mas também com adultos. Assim, entende-se que o ato de desenhar é uma forma de mostrar como se percebe a vida. Segundo Derdyk (2010, p. 110):

O desenho não é mera cópia, reprodução mecânica do original. É sempre uma interpretação, elaborando correspondências, relacionando, simbolizando, atribuindo novas configurações ao original. $O$ desenho traduz uma nova visão porque traduz um pensamento, revela um conceito.

O desenho por se tratar de uma forma de linguagem simples e direta é bastante utilizado em pesquisas destinadas ao público infantil. As representações dos símbolos trazem consigo uma composição de significados de grande relevância para as crianças. Ao expressarem suas opiniões, ideias e vivências por meio de uma técnica lúdica, proporciona à sociedade adulta a oportunidade de conhecer o universo infantil.

\section{BIBLIOTECA COMUNITÁRIA BRUNO FENZL}

A Biblioteca Bruno Fenzl se originou dentro do Instituto Ampliar que é uma Organização não Governamental (ONG) derivada de um projeto de extensão da Universidade Federal do Pará, Centro de Filosofia e Ciências Humanas (CFCH), com a finalidade de desenvolver trabalhos de sensibilização ambiental nas praias de Caruará, Marahu e Paraiso na llha de Mosqueiro Belém-PA, desenvolvido desde 1998. O Instituto Ampliar está localizado na 
Estrada de Caruara, S/N - Travessa Trópico de Câncer, 61, próximo à Praça do Carananduba na llha de Mosqueiro, Belém - Pará.

O Relatório de Atividade do Instituto Ampliar (2014) diz que a Biblioteca "Bruno Fenzl" tem parceria com o CENTUR - Fundação Cultural Tancredo Neves e com o curso de Biblioteconomia da Universidade Federal do Pará (UFPA). A Faculdade de Biblioteconomia, colabora com o projeto desde 2014, atuando com um projeto de extensão do curso de biblioteconomia, envolvendo professores e alunos para otimizar a organização da Biblioteca Bruno Fenzl, assim, oferecer a participação de alunos em atividades de promoção da leitura, como hora do conto, gincanas etc.

$\mathrm{O}$ acervo da biblioteca é composto por materiais diversificados como obras de referência; periódicos adultos, como jornais e revistas; obras infantis como gibis, livros didáticos e paradidáticos; literatura infanto-juvenil; literatura em geral com foco na região e livros técnicos de diversas áreas do conhecimento. Também dispõe de CD's e DVD's. Pelo que dispõe no acervo a biblioteca tem pretensão de atender um público de estudantes que vão desde a educação infantil até os universitários, mas também pode atender usuários que estão fora da escola, como donas de casa e trabalhadores em geral, moradores das comunidades circunvizinhas.

A diversificação do acervo se dá, devido a formação da coleção ser na modalidade doação, e por isso, sempre que um novo grupo de livros são doados, os alunos e professores atuantes no projeto de extensão, fazem uma avaliação da coleção, para descartar aqueles que não devem fazer parte do acervo.

A presidente do Instituto Ampliar, no período de 2014-2016, Profa. Dra. Maria de Fátima Carneiro da Conceição relatou que no decorrer do projeto, percebeu-se a presença muito intensa de crianças e adolescentes no local, que por sua vez, precisavam de estímulo na formação intelectual. Pensando nessa percepção, é que - Instituto começou a arrecadar livros e outros materiais informacionais provenientes de doações com o objetivo de montar a biblioteca que começou a funcionar efetivamente no ano de 2013.

No Relatório de Atividade do Instituto Ampliar (2014) estão descritas as atividades complementares desenvolvidas pela biblioteca a fim de torná-la cada vez mais ativa e com isso atrair um público maior de usuários por meio do "Projeto Tagarela" que objetiva incentivar o hábito da leitura das crianças por meio de atividades lúdicas tais como: pinturas, contação de histórias, desenhos, sessão de cinema e brincadeiras infantis etc., e do "Projeto Sala de Leitura Ampliar", que oferece atividades de 
formação intelectual básica de leituras de cunho educacional, cultural, artístico e conscientização ambiental.

\section{METODOLOGIA}

O estudo possui uma abordagem qualitativa com o intuito de encontrar as respostas para o problema a ser investigado: Como a Biblioteca Comunitária Bruno Fenzl contribui para dar apoio educacional, bem como incentivo à leitura aos estudantes pertencentes à comunidade de Mosqueiro, distrito de Belém-PA?

Para Minayo (2001), a pesquisa qualitativa trabalha com o universo de significados, motivos, aspirações, crenças, valores e atitudes onde processos e fenômenos não se reduzem à operacionalização de variáveis. A pesquisa terá caráter descritivo, pois visa descrever as características dos usuários referentes aos seus gostos, ao seu comportamento e as atividades que mais despertam o interesse pela leitura e o bom rendimento escolar, quais suas necessidades e impressões acerca dos serviços oferecidos pela Biblioteca Bruno Fenzl.

A coleta de dados se deu por meio de entrevistas individuais, seguindo um roteiro estruturado, utilizando-se o desenho como procedimento para coleta das informações desejadas. Para a análise interpretativa dos desenhos buscou-se relacionar as produções gráficas às suas respectivas explicações verbais levando em consideração todo o processo de produção. A pesquisa contou com a participação de 2 crianças e 6 adolescentes, com faixa etária variando entre 10 a 14 anos, havia apenas dois participantes do sexo feminino. A pesquisa teve como pré-requisito a escolha de sujeitos que participavam do Projeto Sala de Leitura que é integrante da biblioteca e funciona aos sábados.

\section{ANÁLISE DOS DADOS}

No processo de interpretação e análise dos dados, as respostas afins foram agrupadas visando obter um melhor entendimento dos dados coletados. Conforme o quadro abaixo: 
Quadro 01 - Agrupamento das respostas análogas das questões da entrevista

\begin{tabular}{|c|c|c|c|}
\hline Sujeitos & Tipos de desenhos & Questões de 5 a 11 & Categoria \\
\hline $\begin{array}{c}\text { (S1), (S4), } \\
(\mathrm{S} 5),(\mathrm{S} 7) \mathrm{e} \\
(\mathrm{S} 8)\end{array}$ & $\begin{array}{c}\text { Desenharam a } \\
\text { biblioteca e crianças } \\
\text { com livros (citaram a } \\
\text { leitura do livro). }\end{array}$ & \multirow{2}{*}{$\begin{array}{c}\text { 5) Que atividades } \\
\text { oferecidas pela } \\
\text { biblioteca mais ajudam } \\
\text { no seu desempenho } \\
\text { escolar? }\end{array}$} & \multirow{4}{*}{$\begin{array}{c}\text { Ações que } \\
\text { contribuem para } \\
\text { auxiliar os } \\
\text { estudantes em } \\
\text { suas atividades } \\
\text { educacionais. }\end{array}$} \\
\hline $\begin{array}{c}\text { (S2), (S3) e } \\
\text { (S6) }\end{array}$ & $\begin{array}{l}\text { Desenharam } \\
\text { computadores } \\
\text { representando o uso } \\
\text { da internet na } \\
\text { pesquisa. }\end{array}$ & & \\
\hline $\begin{array}{l}\text { (S1), (S2), } \\
\text { (S3), (S4), } \\
\text { (S5), (S6), } \\
\text { (S7) e (S8) }\end{array}$ & $\begin{array}{c}\text { Desenharam um } \\
\text { campo de futebol } \\
\text { (fugiram do objetivo da } \\
\text { pergunta). }\end{array}$ & $\begin{array}{c}\text { 6) Que atividades } \\
\text { desenvolvidas pela } \\
\text { biblioteca você mais } \\
\text { gosta? }\end{array}$ & \\
\hline $\begin{array}{l}\text { (S1), (S2), } \\
\text { (S3), (S4), } \\
\text { (S5), (S6), } \\
\text { (S7) e (S8) }\end{array}$ & $\begin{array}{l}\text { Desenharam o livro e } \\
\text { crianças lendo. } \\
\text { (representação da } \\
\text { melhora no } \\
\text { desempenho leitor). }\end{array}$ & $\begin{array}{l}\text { 7) O que mudou no } \\
\text { seu desempenho } \\
\text { escolar depois que } \\
\text { começou a frequentar } \\
\text { a biblioteca? }\end{array}$ & \\
\hline $\begin{array}{c}\text { (S1), (S2) e } \\
\text { (S3) }\end{array}$ & $\begin{array}{l}\text { Desenharam um } \\
\text { computador para } \\
\text { representar o uso da } \\
\text { internet. }\end{array}$ & \multirow[t]{2}{*}{$\begin{array}{l}\text { 8) Que tipo de material } \\
\text { ou assunto você mais } \\
\text { utiliza na biblioteca? }\end{array}$} & \multirow{2}{*}{$\begin{array}{c}\text { Averiguar o tipo } \\
\text { de assunto ou } \\
\text { fonte } \\
\text { informacional } \\
\text { mais consultada } \\
\text { pelos usuários. }\end{array}$} \\
\hline $\begin{array}{l}\text { (S4), (S5), } \\
(\mathrm{S} 6),(\mathrm{S} 7) \mathrm{e} \\
(\mathrm{S} 8)\end{array}$ & Desenharam o livro. & & \\
\hline $\begin{array}{l}\text { (S1), (S6), } \\
\text { (S7) e (S8) }\end{array}$ & $\begin{array}{c}\text { Desenharam livros } \\
\text { para representar a } \\
\text { necessidade de livros } \\
\text { infanto-juvenis mais } \\
\text { atualizados. }\end{array}$ & \multirow[t]{4}{*}{$\begin{array}{c}\text { 9) O que você acha } \\
\text { que precisa melhorar } \\
\text { na Biblioteca Bruno } \\
\text { Fenzl? }\end{array}$} & \multirow[t]{4}{*}{$\begin{array}{c}\text { Verificar as } \\
\text { impressões dos } \\
\text { usuários acerca } \\
\text { dos serviços } \\
\text { oferecidos pela } \\
\text { biblioteca. }\end{array}$} \\
\hline (S2) e (S3) & $\begin{array}{c}\text { Desenharam a } \\
\text { biblioteca trancada } \\
\text { representando a } \\
\text { dificuldade de acesso. }\end{array}$ & & \\
\hline (S4) & $\begin{array}{l}\text { Desenhou um campo } \\
\text { de futebol, assim } \\
\text { fugindo do objetivo da } \\
\text { pergunta. }\end{array}$ & & \\
\hline (S5) & $\begin{array}{l}\text { Desenhou várias } \\
\text { crianças } \\
\text { representando a } \\
\text { possibilidade da } \\
\text { biblioteca receber } \\
\text { mais usuários. }\end{array}$ & & \\
\hline
\end{tabular}


continuação

\begin{tabular}{|c|c|c|c|}
\hline Sujeitos & Tipos de desenhos & Questões de 5 a 11 & Categoria \\
\hline $\begin{array}{l}\text { (S1), (S2), } \\
\text { (S3), (S4), } \\
\text { (S6) e (S7) }\end{array}$ & $\begin{array}{c}\text { Desenharam o Instituto } \\
\text { Ampliar com uma pista } \\
\text { longa representando a } \\
\text { distância e dificuldade } \\
\text { ao acesso. }\end{array}$ & \multirow[t]{2}{*}{$\begin{array}{l}\text { 10) O que você acha } \\
\text { que está impedindo de } \\
\text { mais crianças } \\
\text { frequentarem a } \\
\text { biblioteca? }\end{array}$} & \\
\hline (S5) e (S8) & \begin{tabular}{|c|} 
Desenharam a mãe \\
brigando com o filho \\
para que ele fosse \\
trabalhar ao invés de ir \\
para o projeto da \\
biblioteca.
\end{tabular} & & \\
\hline $\begin{array}{c}\text { (S1), (S7) e } \\
\text { (S8) }\end{array}$ & \begin{tabular}{|c|}
$\begin{array}{c}\text { Desenho de livros } \\
\text { representando a } \\
\text { organização da } \\
\text { biblioteca. }\end{array}$ \\
\end{tabular} & \multirow[t]{3}{*}{$\begin{array}{l}\text { 11) Como você } \\
\text { gostaria de ver a } \\
\text { biblioteca? }\end{array}$} & \\
\hline (S2) e (S3) & \begin{tabular}{|c|} 
Desenharam um \\
$\begin{array}{c}\text { onibus para melhorar } \\
\text { o acesso ao local da } \\
\text { biblioteca. }\end{array}$ \\
\end{tabular} & & \\
\hline $\begin{array}{c}\text { (S4), (S5) e } \\
\text { (S6) }\end{array}$ & $\begin{array}{l}\text { Desenharam uma } \\
\text { piscina, brinquedos, } \\
\text { crianças brincando } \\
\text { representando a } \\
\text { importância do lúdico. }\end{array}$ & & \\
\hline
\end{tabular}

Fonte: Dados levantados por esta pesquisa, 2016.

Os dados apresentados no quadro mostram que as atividades oferecidas pelo Projeto Sala de Leitura e pesquisa na internet, de acordo com as opiniões dos entrevistados, são as atividades que mais contribuem para o desempenho escolar dos respondentes. Por meio dos desenhos e verbalizações foi possível perceber que a maioria dos entrevistados atribui à leitura do livro impresso como o principal suporte de atividades responsáveis por ajudarem em seus estudos. Vejamos um exemplo abaixo (Figura 1):

Figura 1 - Desenho realizado pelo sujeito S8

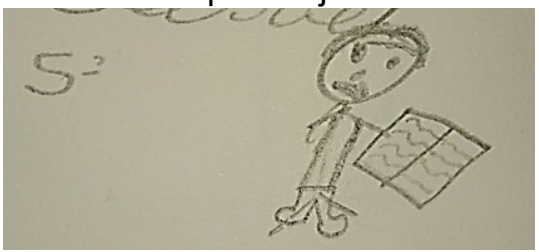

Fonte: Dados levantados por esta pesquisa, 2016. 
Também se encontra nos desenhos das crianças e adolescentes a constatação de que o uso dos recursos eletrônicos é uma realidade mesmo naqueles que podem ser considerados como excluídos digitais. Como a Figura 2 ilustra, verifica-se que o computador representa a utilização da internet como fonte de pesquisa no Infocentro, também disponibilizada pelo Instituto Ampliar por meio do Projeto Navega Pará.

Figura 2 - Desenho realizado pelo Sujeito S2)

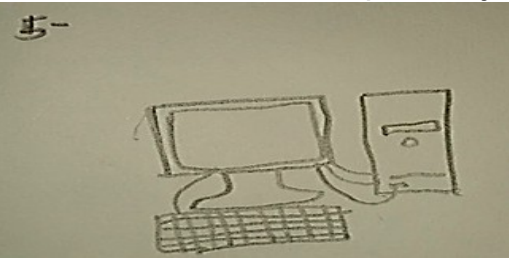

Fonte: Dados levantados por esta pesquisa, 2016.

O desenho de computadores e livros voltou a ser registrado no que se refere ao tipo de fonte informacional mais utilizada pelos usuários. Sobre a atividade que mais atrai os entrevistados, o futebol foi o fator unanime que mais atrai as crianças para o projeto sala de leitura e consequentemente biblioteca. O futebol é um recurso utilizado como espécie de premiação aos usuários que participam do Projeto Sala de Leitura promovido pela biblioteca, pois sempre ao final das atividades desenvolvidas, os mesmos são liberados para brincar. Por esse motivo observa-se a presença maior de crianças e jovens do sexo masculino.

As mediadoras desse projeto disseram que apesar do futebol ajudar a atrair usuários para o espaço, esperam que um dia eles se habituem a frequentar a biblioteca sem necessidade de que esse esporte seja o principal meio de atração. Na representação gráfica (Figura 3) é possível observar crianças jogando futebol.

Figura 3 - Desenho realizado pelo sujeito S7

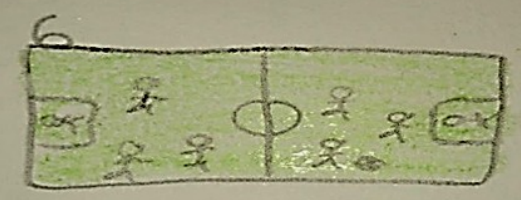

Fonte: Dados levantados por esta pesquisa, 2016. 
Nesta perspectiva, a criança por meio do desenho é capaz de retratar sua realidade, mostrando que seu espaço lúdico também é importante. Seus traços da infância são expressos nos desenhos porque é algo que ela vivencia e por isso, tem significado.

$\mathrm{Na}$ questão que buscou entender que melhorias os entrevistados tiveram no seu desempenho escolar ao frequentar a biblioteca e seu projeto sala de leitura, os sujeitos da pesquisa relataram que o projeto os ajudou a obter um avanço no domínio da leitura.

Figura 4 - Desenho realizado pelo sujeito S6

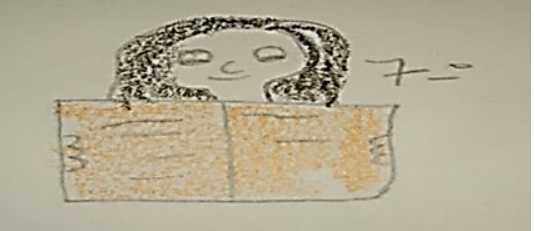

Fonte: Dados levantados por esta pesquisa, 2016.

A figura 4 apresenta uma menina lendo um livro, mostrando seu interesse na leitura. A entrevistada que fez o desenho, relatou grande entusiasmo pela leitura e fez um espécie de autoretrato. É uma daquelas que frequenta a biblioteca sem o interesse pelo futebol depois das atividades da sala de leitura. Durante o aprofundamento com ela a respeito do desenho, demostrou que vem ao Instituto Ampliar a procura de livros e não com interesse pelo futebol, talvez por ser menina, e ainda no imaginário popular fica convencionado que futebol é coisa de menino.

No que refere as impressões dos usuários acerca das melhorias que precisam ser feitas no espaço, as respostas foram referentes à necessidade de um acervo mais atualizado e destinadas ao público infanto-juvenil. A necessária facilidade de acesso ao Instituto Ampliar também foi registrada pelos entrevistados.

Figura 5 - Desenho realizado pelo sujeito S3

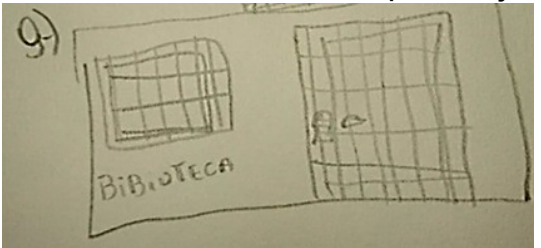

Fonte: Dados levantados por esta pesquisa, 2016. 
Na figura 5 nota-se a faixada da biblioteca, mas com grades, representando a dificuldade em seu acesso. As grades e o cadeado simbolizam o desejo de ver a biblioteca aberta mais vezes. A dificuldade no acesso se deve ao fato da biblioteca está passando por um processo de reorganização.

$\mathrm{Na}$ décima questão, buscou-se entender o motivo de de outras crianças não estarem frequentando o projeto. A distância foi o fator mais mencionado, como é possível observar na figura 6 . Salienta-se que o serviço de transporte coletivo no distrito de Mosqueiro, fora do tempo das férias, quando fica tomado de turistas, é precário.

Figura 6 - Desenho realizado pelo sujeito S4

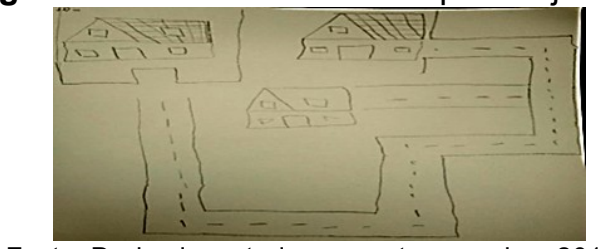

Fonte: Dados levantados por esta pesquisa, 2016.

Assim, a figura 6 simboliza a dificuldade para chegar ao local, expresso por uma longa estrada. Isto ocorre pela dificuldade de usar os transportes públicos no distrito de Mosqueiro, parte dele é feito pelo transporte alternativo, que não permite o uso da meia-passagem. $U$, direito dos estudantes, o que onera os custos de deslocamento da criança/adolescente para o Instituto Ampliar. Assim, os frequentadores da biblioteca e dos projetos se resumem aqueles que moram a uma distância que permite chegar a pé ao local onde funciona a biblioteca.

\section{DISCUSSÃO GERAL DOS RESULTADOS}

Quanto a análise dos desenhos no que se refere às atividades mais atrativas, houve uniformidade nas respostas quando todas relacionaram o futebol como fator preponderante para frequentar o espaço. Entende-se que o lúdico pode ser um aliado para chamar o público infanto-juvenil, porém é necessário outras formas de atividades que mostrem a biblioteca como um importante agente social e fonte de aprendizagem que vai além de um local de entretenimento, mas sim como uma porta de entrada para a formação de um cidadão com pensamento crítico e agente de transformação social.

Sobre a questão da melhoria no desempenho escolar, as 
atividades de leitura têm uma ação direta no processo educativo na medida em que estimulam os usuários a ultrapassarem a simples decodificação mecânica de palavras, buscando ler e interpretar com autonomia.

O desenho de computadores obtidos na entrevista com os sujeitos, mostra que o uso da internet vem se tornando mais acessível e bastante utilizado na pesquisa escolar dos que frequentam a biblioteca, mesmo aqueles que podem ser considerados como excluídos digitais.

Na questão que tratou do tipo de material ou assunto mais utilizado pelos entrevistados, foi possível observar que apesar de vivermos na era da internet, o livro impresso ainda é bastante procurado pelos usuários, tanto em leituras de entretenimento quanto em pesquisas escolares. Por isso, na questão que trata das melhorias da biblioteca, prevaleceu a necessidade de livros novos e com títulos atuais destinados ao público infanto-juvenil. Outro fator mencionado, foi a necessidade da presença de mais crianças no espaço, mostrando que entendem a função da biblioteca como agente de transformação e querem que outras pessoas partilhem desse processo.

A questão da acessibilidade também foi discutida na pergunta referente aos impedimentos de outras crianças estarem frequentando o espaço. Sobre isso, os participantes da pesquisa foram quase unanimes em dizer que a biblioteca poderia ser frequentada por outras crianças se houvesse um transporte público que passasse por aquela localidade.

Outro fator importante identificado é a falta de conscientização dos pais sobre a importância desse espaço para a formação intelectual das crianças, que entre outras coisas vai ajudar a mantê-las distante da criminalidade. No decorrer da pesquisa alguns entrevistados relataram que outras crianças não frequentam a biblioteca porque são impedidos por seus pais, haja vista que precisam trabalhar para complementar a renda familiar. Isso de certo modo revela a realidade que vivem, sobre isso Derdyk (1989) revela que as reflexões acerca do desenho podem dizer muito de quem o produziu, se desenha para contar suas descobertas e vivências.

Apesar das dificuldades relatadas, a pesquisa revelou que a biblioteca Bruno Fenzl vem cumprindo seu papel social que é levar a leitura reflexiva, propagando a educação e formação sociocultural. $\mathrm{O}$ projeto "Sala de Leitura Ampliar", desenvolvido pela biblioteca Bruno Fenzl, vem oferecendo às crianças e jovens moradores da llha de Mosqueiro, atividades de formação intelectual básica, com leituras de 
cunho educacional, cultural, artístico e conscientização ambiental, criando assim, um espaço que promove o prazer na leitura.

\section{CONSIDERAÇÕES FINAIS}

Os participantes da pesquisa por meio do desenho mostraram que apesar de vivermos na era da tecnologia, ainda assim, veem o livro impresso como um suporte bastante atrativo quando se trata de práticas de leitura. Entretanto, a biblioteca precisa superar algumas dificuldades como o acervo, que mesmo sendo extenso necessita de obras infanto-juvenis mais atualizadas. Isto se deve devido ao fato de o acervo ser formado em sua maioria por doação, quase sempre de alguém que tendo se aposentado levou sua coleção para o Instituto Ampliar. O acervo é rico e tem inclusive grandes clássicos, mas como é frequentada mais pelas crianças, o acervo de adultos, que é mais interessante não vem sendo utilizado, sendo necessário incentivar os adultos que frequentam o local, também para o uso da biblioteca.

Isso revela a necessidade de haver maior divulgação do trabalho realizado na biblioteca a fim de atrair mais usuários, mostrando também aos pais das crianças e adolescentes da comunidade a qual está inserida, que além de ser um espaço recreativo e de interação, promove conhecimento e cultura, cumprindo assim um papel educativo na medida em atua em prol da comunidade formando leitores críticos.

A dificuldade de acesso devido à distância é outro problema relatado pelos participantes da pesquisa. Trata-se de algo que vem sendo requerido pela comunidade porque atinge a todos, pela falta de transporte.

\section{REFERÊNCIAS}

ALMEIDA JÚNIOR, Oswaldo Francisco de. Bibliotecas públicas e bibliotecas alternativas. Londrina: Ed. UEL, 1997.

$\mathrm{BOHM}$, Marcelo Ribeiro. Estudo de perfil e necessidades informacionais dos usuários da Biblioteca Livros Sobre Trilhos: Estação Mercado. 2009. 74 f. Trabalho de Conclusão de Curso (Bacharel em Biblioteconomia). Curso de Biblioteconomia. Universidade Federal do Rio Grande do Sul, Porto Alegre, 2009.2 Disponivel em: http://www.lume.ufrgs.br/bitstream/handle/10183/ 22695/000740216.pdf?sequence=1. Acesso em: 27 jul. 2015. 
CASTRO, Carla Jeane dos Santos; OLIVEIRA, Milra Alves de; ALVES, Thainara de Jesus. Biblioteca comunitária "Ler pra Valer": análise do comportamento informacional. In: ENCONTRO REGIONAL DOS ESTUDANTES DE BIBLIOTECONOMIA, DOCUMENTAÇÃO, CIÊNCIA E GESTÃO DA INFORMAÇÃO - EREBD, 17, 2014. Anais... Disponível em: http://www.erebdfortaleza2014.ufc.br/gt/GT4/Biblioteca\%20Comunit\%C3\%A 1 ria\%20Ler\%20 pra\%20Valer.pdf>. Acesso em: 21 abr. 2016.

DERDYK, Edith. Formas de pensar o desenho. São Paulo: Scipione, 1989.

DERDYK, Edith. Formas de Pensar o Desenho: desenvolvimento do Grafismo Infantil. Porto Alegre: Zouk, 2010.

INSTITUTO AMPLIAR. Relatório de atividades 2014. Belém, 2014.

MACHADO, Elisa Campos. Bibliotecas comunitárias como prática social no Brasil. 2008. 184 f. Tese (Doutorado em Ciência da Informação) Escola de Comunicações e Artes, Universidade de São Paulo, São Paulo, 2008. Disponível em: Acesso em: 30 jul. 2015.

MINAYO, Maria Cecília de Souza (org.). Pesquisa Social. Teoria, método e criatividade. Petrópolis: Vozes, 2001.

WESSFLL, Cyntia Silva. Bibliotecas Comunitárias e cidadania: uma aproximação teórica. 2011. 44 f. TCC (Graduação) - Curso de Biblioteconomia, Departamento de Ciências da Informação, Universidade Federal do Rio Grande do Sul, Porto Alegre, 2011. Disponível em: https://www.lume.ufrgs.br/bitstream/handle/10183/37502/000819872.pdf? sequence=1. Acesso em: 07 jan. 2016. 